\title{
SKIN-SPAR FAILURE DETECTION OF A COMPOSITE WINGLET USING FBG SENSORS
}

\begin{abstract}
Winglets are introduced into modern aircraft to reduce wing aerodynamic drag and to consequently optimize the fuel burn per mission. In order to be aerodynamically effective, these devices are installed at the wing tip section; this wing region is generally characterized by relevant oscillations induced by flights maneuvers and gust. The present work is focused on the validation of a continuous monitoring system based on fiber Bragg grating sensors and frequency domain analysis to detect physical condition of a skin-spar bonding failure in a composite winglet for in-service purposes. Optical fibers are used as deformation sensors. Short Time Fast Fourier Transform (STFT) analysis is applied to analyze the occurrence of structural response deviations on the base of strain data. Obtained results showed high accuracy in estimating static and dynamic deformations and great potentials in detecting structural failure occurrences.
\end{abstract}

\section{Introduction}

The Structural Health Monitoring (SHM) may be intended as the ability to monitor structures by means of embedded or attached sensors and to utilize the acquired data to assess the state of the structure. Over the last ten years, researchers have made significant advances in developing Non Destructive Evaluation (NDE) methods for SHM, and they have developed the hardware and software needed for the analysis and fast data transfer of the results.

The SHM is differently defined by various research groups. For instance, it is defined as a system with the ability to detect and understand adverse "changes" in a structure in order to improve reliability and reduce life cycle costs $[1,2]$.

\footnotetext{
${ }^{1}$ Italian Aerospace Research Center, CIRA Via Maiorise, 1, 81043 Capua, Italy. Email: m.ciminello@cira.it

${ }^{2}$ University of Naples "Federico II", Department of Industrial Engineering - Aerospace Division, Via Claudio, 21, 80125 Naples, Italy.

${ }^{3}$ NOVOTECH s.r.l. - Aerospace Advanced Technology, P.le D’Annunzio 15, 80125 Naples, Italy.
} 
The greatest challenge in designing a SHM system is knowing what "changes" to look for and how to identify them. The characteristics of damage in a particular structure play a key role in defining the architecture of the SHM system. The resulting "changes" or damage signature, will dictate the type of sensors that are required, which in turn determines the requirements for the rest of the components in the system. The great part of the current research focuses on the relation between various sensors and their sensitivity [3]. The sources of faults can result from fatigue, corrosion, impacts, excessive loads, unforeseen conditions, etc.

For aircraft applications, the uses of SHM technologies for future aircraft will not only enable new possibilities for maintenance concepts, but will have a significant influence on design and assembling concepts. SHM is expected to be one of the key technologies for controlling the structural integrity of future aircraft providing both maintenance and weight saving benefits. The continuous and high demand of increasingly lighter structures is leading to a wide application of the damage tolerant structures; from this the growing need to monitor the structural components either before and after that the damage is occurred. The structural health monitoring is likely to be used in identifying failures in aircraft, even in the early damage state, which would also be a boon to the commercial aircraft industry. In addition, it can increase the structures life beyond the limits currently imposed by the regulation. The performances of such a system are connected with sensing signals. The sensors capabilities significantly influence the application of SHM systems, as well as the methods used for damage detection are strictly connected with the sensors integration and sensitivity.

The most popular sensors used in SHM are piezoelectric (PZT) transducers and optic fiber Bragg grating (FBG) sensors. Regardless of the type of sensors used, the SHM techniques can be split in two different classes, the "global scale" and "local scale" methods. The "global scale" methods detect a damage through the changes introduced by damage in the structural modal properties (natural frequencies, modal shapes, etc.) [4-7]. The application of these methods is limited by the detection of only big damage, since a little damage cannot introduce considerable changes in the structure modal parameters. Conversely, the "local scale" methods allow for detecting a damage also when it is still of little dimensions, but they require a consistent number of sensors in order to guarantee adequate coverage of the whole system [8-11]. The number of sensors can drastically get off if the FBG sensors are used thanks to their capabilities to monitor more areas with a single optical fiber.

In the past years, FBG sensors have been the subject of many investigations activities and commercial products are now appearing on the market. Researchers have been particularly active in developing fiber optic sensors systems for SHM [12-14]. In aeronautical applications, a number of sensors for SHM are designed and integrated in trailing edge, leading edge, and composite winglet subsystems for large civil transport aircraft [15-17]. The fiber Bragg gratings are successful in measuring the strain in the spar, including the shock loads induced by both lightning 
and bird strike tests [11]. Continuous monitoring of structural loads especially in high-stress regions could lead to ongoing improvements in design that would avoid the generation of excessive strains. It is clear that structural sensor systems could substantially reduce life-cycle cost as it would provide the means of checking structures quite literally from the birth to the dismissal.

This paper reports the integration and validation of an FBG sensors system able to detect continuous structural response of a composite winglet under load. This ongoing study funded by the Italian Ministry of the Research and Innovation, focused, among other things, on the development of SHM methods to be tested on new generation Glass Fiber-Reinforced Plastic (GFRP) blended winglets for a general aviation aircraft (P2006 or similar). The final goal is the realization of a robust yet very light wing with smart functionalities (real time health monitoring, low drag, fuel consumption reduction).

In what follows, a preliminary functionality test of the SHM system integrated on a full scale demonstrator, provided by the aircraft company, is performed. The finite element model is used to output the strain map over the outer surface of the composite winglet. The FBG are then integrated along the maximum excitation direction, according to the FE simulation and taking account of the experienced strain field not exceeding the allowable values. The calibration of the sensors baseline readings is then assessed by applying a static load to the winglet tip. Deformation data are on-line processed in frequency domain to detect physical condition of an "induced" skin-spar failure during cyclic load. Results gained by the sensing system once embedded within such an adaptive smart structure would provide the necessary on-line information on its structural health.

\section{Test article}

Winglets are designed to increase the effective airfoil aspect ratio, obtaining benefits in terms of induced drag reduction; on the other side, winglets have the drawback to induce wing root bending moment increase. Even if the winglet is not a primary structure, it has to be lightweight and strong at the same time, so to reduce fuel burn and to be flight-safe. A composite winglet of a general aviation aircraft is described (Fig. 1).

The winglet is manufactured as two single-part shells (top and bottom). It is realized using a plane-wave fabric laminae made of fiberglass infused with epoxy resin and foam coring. The structural robustness and stability of the winglet are improved using a spar made of a high-performance low-density foam core (Fig. 2a) that starts at the root section and reaches the $3 / 4$ of the winglet height. In addition, different lay-ups, with cores foam, are used for upper and lower winglet surfaces (Fig. 2b).

The mechanical properties of the materials used are recapped in Table 1, while the lay-ups are shown in Table 2. 


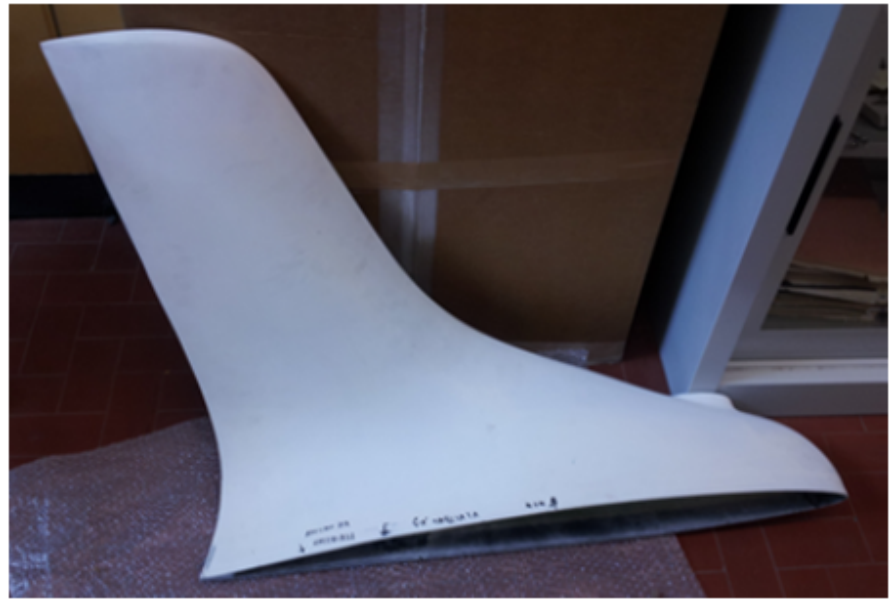

Fig. 1. The investigated composite full scale blended winglet

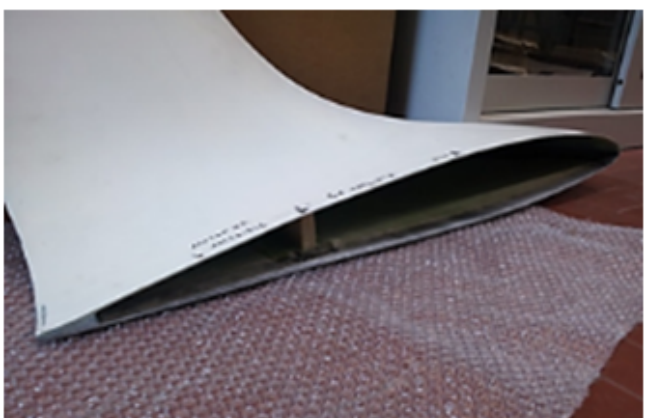

(a)

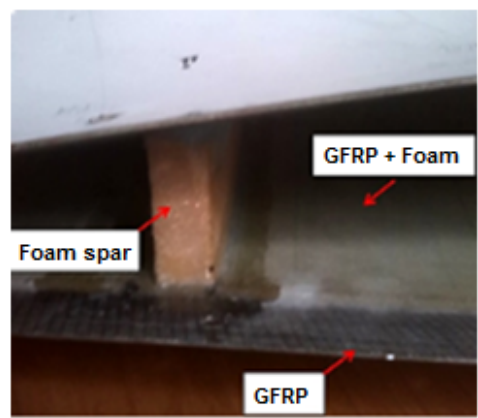

(b)

Fig. 2. Section view at winglet root (a) and particular on the skin-spar junction (b)

Table 1.

Materials properties

\begin{tabular}{|l|c|c|c|c|}
\hline Material properties & Symbol & Units & Foam & $\begin{array}{c}\text { Glass-Epoxy } \\
\text { unidirectional plies }\end{array}$ \\
\hline Young modulus & $E$ & {$[\mathrm{GPa}]$} & 1.3 & - \\
\hline Longitudinal Young modulus & $E_{1}$ & {$[\mathrm{GPa}]$} & - & 11 \\
\hline Transversal Young modulus & $E_{2}$ & {$[\mathrm{GPa}]$} & - & 6.5 \\
\hline Shear modulus & $G$ & {$[\mathrm{GPa}]$} & 0.303 & - \\
\hline Shear modulus & $G_{12}$ & {$[\mathrm{GPa}]$} & - & 0.4 \\
\hline Poisson's ratio & $v$ & - & 0.32 & 0.3 \\
\hline Mass density & $\rho$ & {$\left[\mathrm{kg} / \mathrm{m}^{3}\right]$} & 112 & 1550 \\
\hline
\end{tabular}


Table 2 .

Stacking sequence of the upper and lower winglet skin

\begin{tabular}{|c|c|l|}
\hline \multicolumn{3}{|c|}{ Upper lay-up } \\
\hline Ply & $\theta$ & Material \\
\hline 1 & $0^{\circ}$ & Glass-Epoxy \\
\hline 2 & $\pm 45^{\circ}$ & Glass-Epoxy \\
\hline 3 & $\pm 45^{\circ}$ & Glass-Epoxy \\
\hline 4 & $\pm 45^{\circ}$ & Glass-Epoxy \\
\hline 5 & $0^{\circ}$ & Foam \\
\hline 6 & $0^{\circ}$ & Glass-Epoxy \\
\hline
\end{tabular}

\begin{tabular}{|c|c|l|}
\hline \multicolumn{3}{|c|}{ Lower lay-up } \\
\hline Ply & $\theta$ & Material \\
\hline 1 & $0^{\circ}$ & Glass-Epoxy \\
\hline 2 & $\pm 45^{\circ}$ & Glass-Epoxy \\
\hline 3 & $\pm 45^{\circ}$ & Glass-Epoxy \\
\hline 4 & $0^{\circ}$ & Foam \\
\hline 5 & $0^{\circ}$ & Glass-Epoxy \\
\hline
\end{tabular}

\subsection{Finite Element modelling and validation}

The application of FBG sensors for SHM purpose requires a numerical investigation to identify the position hot points to be monitored. The winglet FE model is developed using 4-nodes quadrilateral elements (CQUAD4) for the skin and the 8-nodes solid elements (CHEXA) for the spar (Fig. 3) [18].

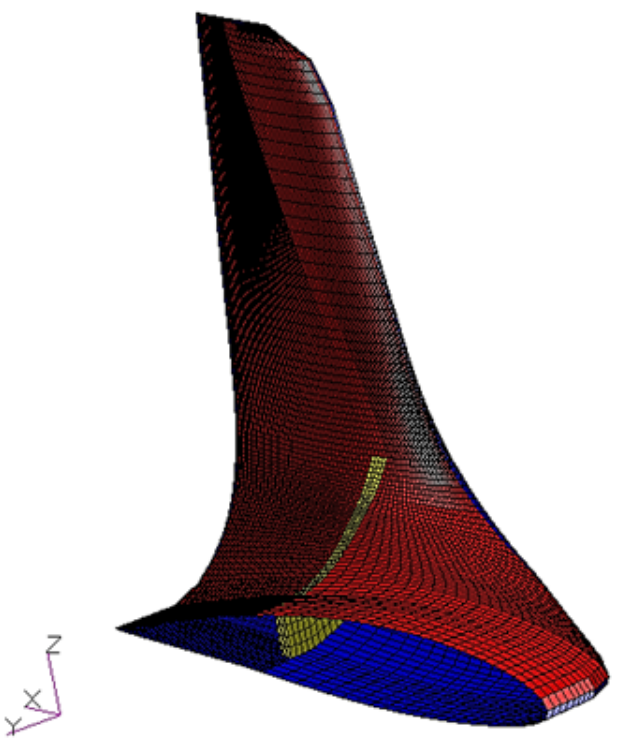

Fig. 3. FEM views of the winglet

The FE model is validated through static test. The results of the static validation is used for the definition of the FBGs location and calibration purpose, as described in the next paragraph.

The experimental set-up of the static test is pictured in Fig. 4a. The winglet is rigidly fixed to a steel support by means of 14 bolts, while the load is uniformly applied at $2 / 3$ from the tip as weight load. The static weight is slightly increased 
from $1 \mathrm{~kg}$ to $28 \mathrm{~kg}$. A laser sensor "LeicoDistroTM A5" is used to measure the displacement of the winglet at the control point. Equivalent conditions are reproduced in the FE model with reference to the boundary conditions, load values, load application area and control point (Fig. 4b).

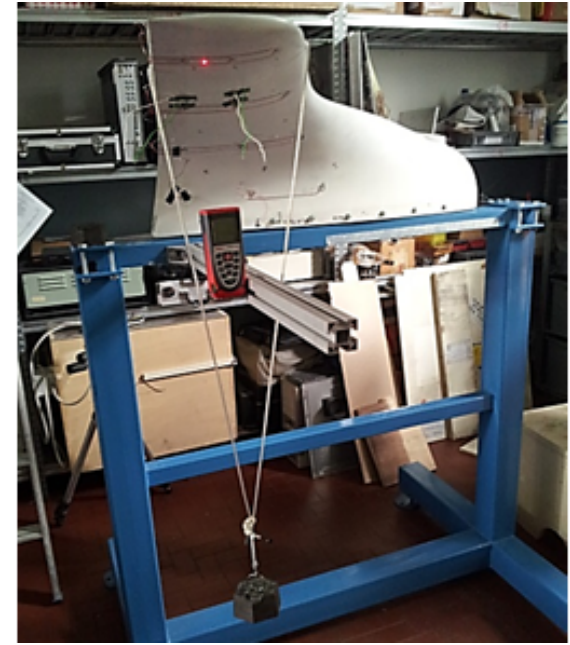

(a)
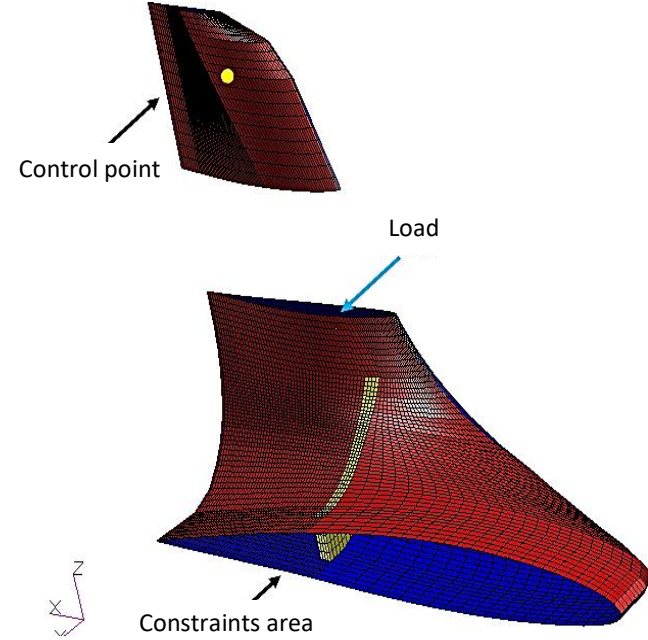

(b)

Fig. 4. Experimental setup (a) and FEM view (b) about the static test

The comparison between numerical and experimental results (Fig. 5) shows that the FE model of the winglet can be assumed fairly representative of the test article from the static point of view.

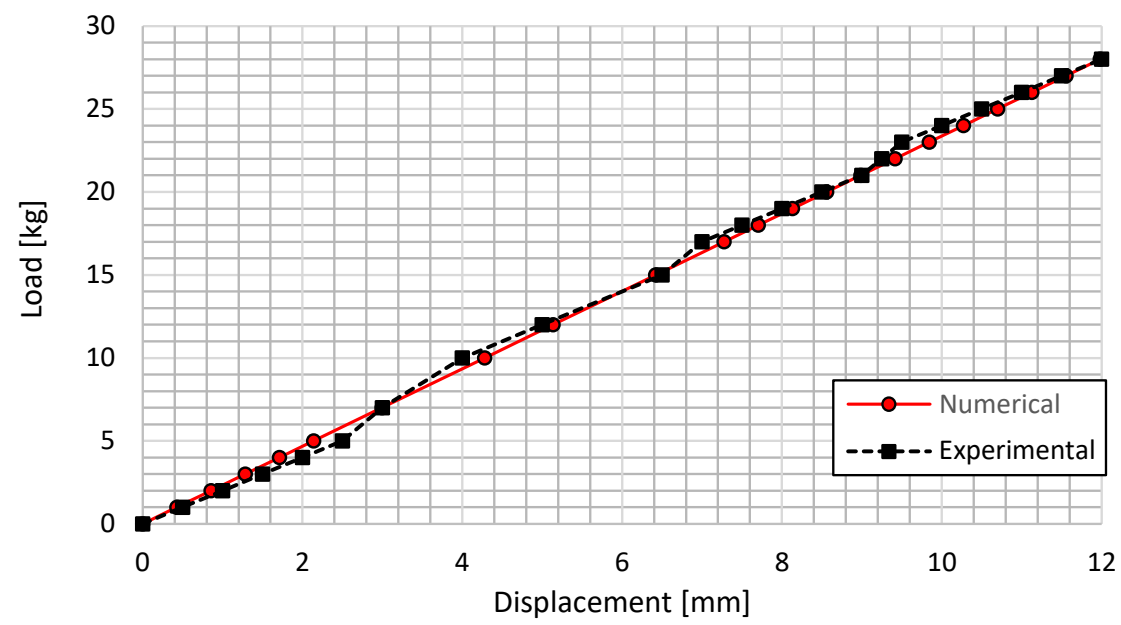

Fig. 5. Test and numerical results of the static validation 


\section{Sensor network design}

The characteristics of the winglet play a key role in defining the architecture of the SHM system. To simplify sensor network installation, being this stage a functionality test of spar-skin debonding detection, the laboratory test is performed by detecting the occurrences of anomalous dynamic response under quasi-static cyclic loading. Sensors are bonded on the outer skin, indeed, the cable integration accounting for accessibility issues and system redundancy for risk mitigation, at this stage, are not taken into consideration.

In addition, in order to detect multi-point structural response by minimally affecting the weight of the test article, a sensor system made by multiplexed FBGs is preferred, thus providing more sensing element on the same "wire". The Bragg grating is, in fact, essentially defined by the period of the microstructure and the index of refraction of the fiber core [19]. This microstructure serves as a wavelength selective mirror: light travelling down the fibre is partially back scattered but these reflections interfere destructively at most wavelengths. At one particular narrow range of wavelengths, constructive interference occurs and light is returned down to the fibre. Maximum reflectivity occurs at the so-called Bragg wavelength $\left(\lambda_{B}\right)$ and depends on the effective index of refraction $n_{e f}$ and on the period $\Lambda$ of the grating according to the well-known Bragg equation:

$$
\lambda_{B}=2 n_{e f} \Lambda \text {. }
$$

The strain dependence of a fiber Bragg grating can be determined by differentiating Eq. (1):

$$
\frac{\Delta \lambda_{B}}{\lambda_{B}}=\frac{\Delta\left(n_{e f} \Lambda\right)}{n_{e f} \Lambda}=\left(1+\frac{1}{n_{e f}} \frac{\partial n_{e f}}{\partial \varepsilon}\right) \Delta \varepsilon=\left(1+p_{e}\right) \Delta \varepsilon=\beta_{\varepsilon} \Delta \varepsilon,
$$

where: $\beta_{\varepsilon}$ is the strain sensitivity of the Bragg grating, $p_{e}$ is the photoelastic constant (variation of index of refraction of silica core with axial tension).

For most silica optical fibers, we assume that the effect of core doping (typically with germanium) is negligible, and thus, taking the commonly quoted photo-elastic coefficient value in the literature for fused silica is:

$$
p_{e}=-0.22
$$

From Eq. (2), the theoretical strain sensitivity for a standard SMF-28 fiber is given by the expression:

$$
S_{\text {theor }}=\frac{\Delta \lambda_{B}}{\Delta \varepsilon}=\beta_{\varepsilon} \lambda_{B}=0.788 \lambda_{B}
$$

According to Eq. (3), it is possible to define the sensitivity for each FBG according to the central wavelength.

Based on this physical principle, different Bragg wavelengths, can be printed on the same fibre, thus drastically reducing the cost and installation efforts, very 
important for full scale applications. In this case, the sensor network is designed in terms of sensors number, position, and ultimate strength. A minimum number of 6 FBGs are integrated on the skin by using a certified structural adhesive MBond 200. The gauge length is $10 \mathrm{~mm}$. Upon validated the FE model, further analyses are conducted in order to calculate the winglet strain distribution useful for the FBGs layout definition. Ultimate strength performances are guaranteed by verifying that the winglet strain distribution at maximum load is not exceeding the sensors strain limits declared by manufacturer. The strain distribution of the winglet skin at maximum load $(30 \mathrm{~kg})$ is pictured in Fig. 6.
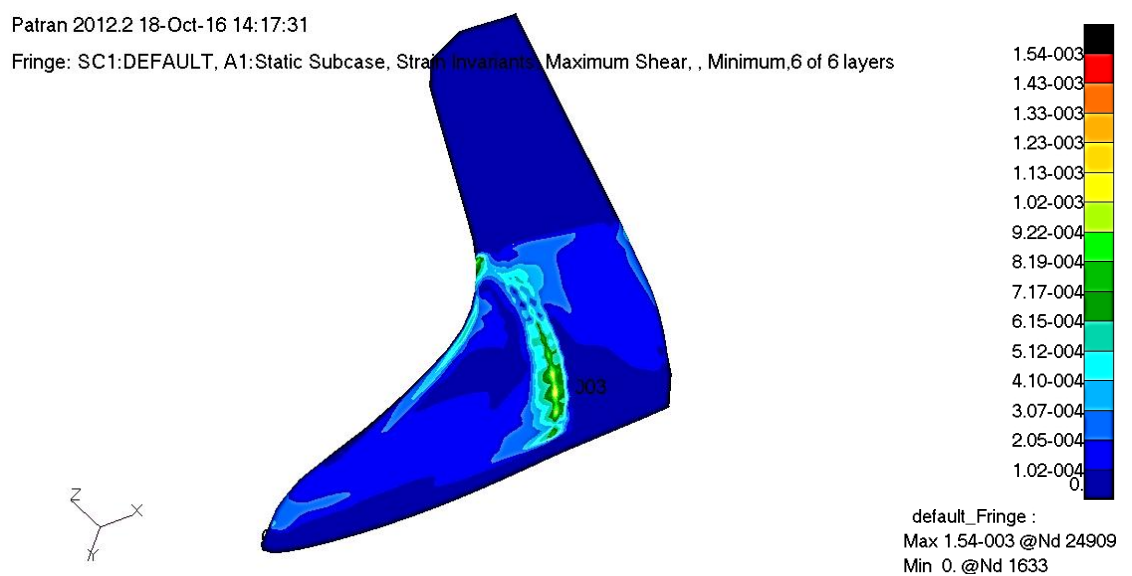

Fig. 6. Microstrain distribution - load condition $30 \mathrm{~kg}$

When the static load of $30 \mathrm{~kg}$ is applied, a maximum strain of about 1100 microstrain is reached, corresponding to the spar-skin connection region that starts at the root and reaches the 3/4 of the height. Three FBGs, namely B1, B2 and B3, are bonded all along this main line as depicted in Fig. 7. In addition, other two regions are also monitored, the leading edge (point $\mathrm{C} 1$ ) and trailing edge (points B1 and B2), where the two single-part shells (top and bottom) are lap-jointed. The FBGs direction follows the maximum excitation to maximize the response.

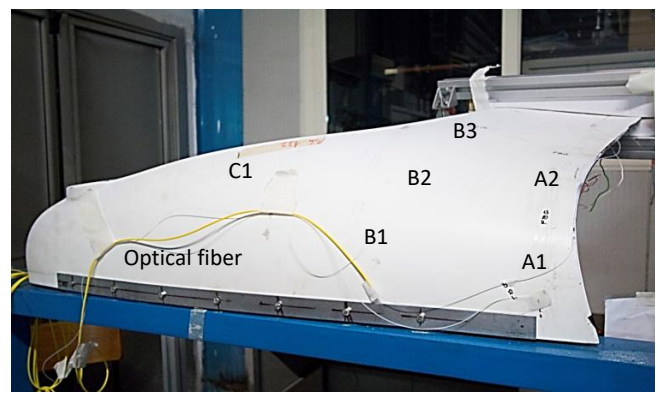

Fig. 7. FBGs points map on the composite winglet 
Before starting the test campaign, a calibration procedure is performed by loading the wingtip, starting from $1 \mathrm{~kg}$ up to $30 \mathrm{~kg}$. The calibration phase has considered four steps during which the initial load, of $1 \mathrm{~kg}$, is gradually increased to $10 \mathrm{~kg}$, then to $20 \mathrm{~kg}$ and finally to $30 \mathrm{~kg}$. At each step, the stability of the sensors reading is gained. As reported in Fig. 8, each sensor experiences linear calibration curves with respect to the applied load, meaning a constant sensitivity within the excitation range.

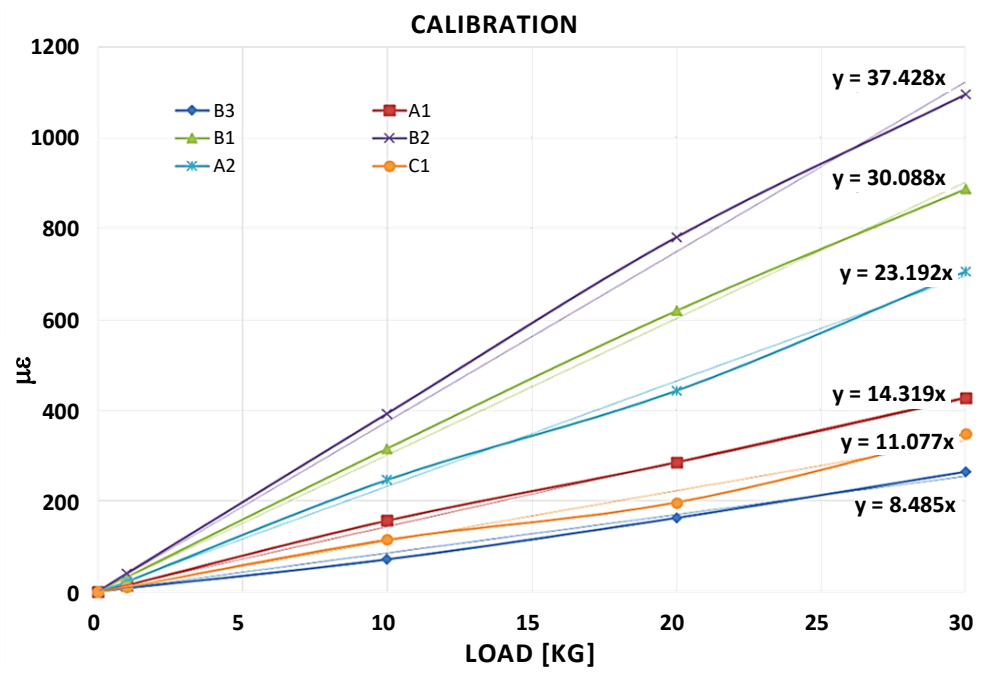

Fig. 8. System sensitivity $[\mu \varepsilon / \mathrm{kg}]$

In Table 3, FBGs main characteristics and sensitivity applied for the strain evaluation are reported.

Table 3.

FBGs sensitivity

\begin{tabular}{|l|c|c|c|c|}
\hline \multirow{2}{*}{ Fiber ID } & $\begin{array}{c}\text { FBG } \\
{[\mathrm{ID}]}\end{array}$ & $\begin{array}{c}\text { Bragg } \\
\text { wavelength } \\
{[\mathrm{nm}]}\end{array}$ & $\begin{array}{c}\text { FBG } \\
\text { sensitivity } \\
(\mathrm{pm} / \mu \varepsilon)\end{array}$ & $\begin{array}{c}\text { FBG } \\
\text { sensitivity } \\
(\mu \varepsilon / \mathrm{kg})\end{array}$ \\
\hline \multirow{2}{*}{ A-Winglet trailing edge } & A1 & 1530 & 1.19 & 14.3 \\
\cline { 2 - 5 } & A2 & 1570 & 1.22 & 23.2 \\
\hline \multirow{3}{*}{ B-Winglet wing box } & B1 & 1530 & 1.19 & 30.1 \\
\cline { 2 - 5 } & B2 & 1550 & 1.21 & 37.4 \\
\cline { 2 - 5 } & B3 & 1570 & 1.22 & 8.5 \\
\hline C-Winglet leading edge & $\mathrm{C} 1$ & 1550 & 1.21 & 11.1 \\
\hline
\end{tabular}

The system sensitivity is applied to verify numerical-experimental correlation of structural strain measurements and sensor placement on the winglet upper skin. Results reported in Fig. 9 show a good correspondence with data analysis. 


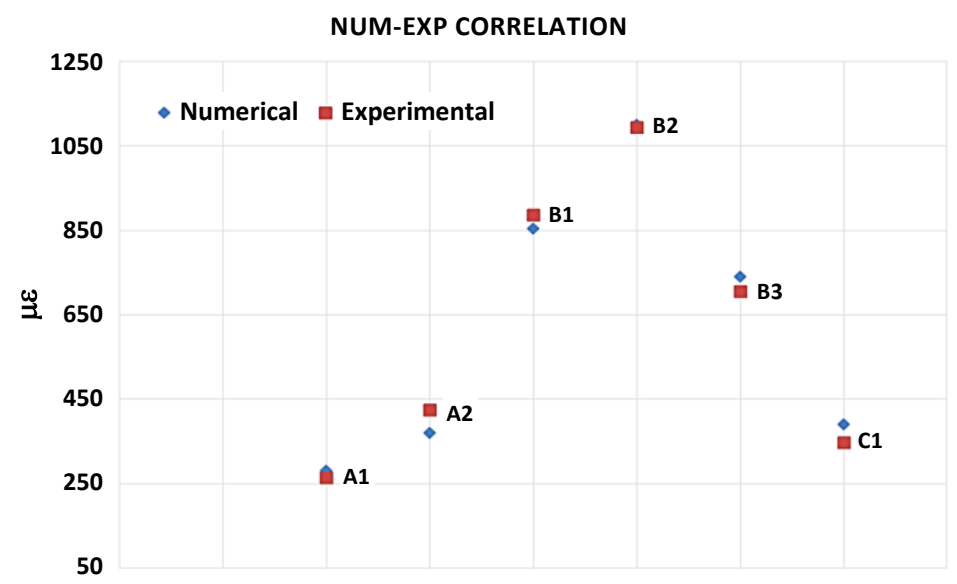

Fig. 9. Numerical and experimental strain data comparison for correlation with $30 \mathrm{~kg}$ load

The weight of the winglet is not taken into account during static and quasistatic measurements. Being the weight an offset value, the corresponding strain are not affecting the response of the sensors. In addition, the occurrences of residual strain, due to gravity force acting on the test article and due to adhesive curing, have been set to zero.

\section{Structural response under dynamic excitation}

In order to verify the occurrence of a debonding failure evaluating the on-line structural response, a quasi-static cyclic test is performed. Similarly to what occurs in metallic materials, the fatigue loads application to composite can lead to failure, while being the maximum alternating stress lower than the static material strength.

A cyclic load, simulating in-service operation, is applied in correspondence of the end section of the winglet, a saddle is mounted (Fig. 10) for the load application.

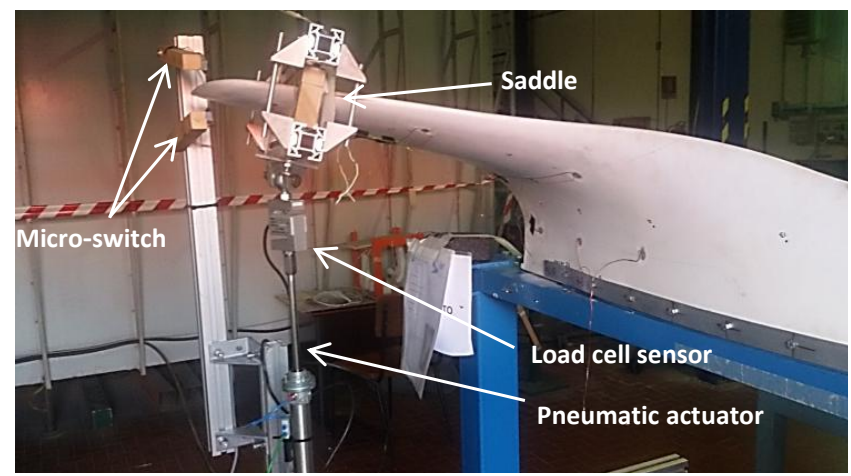

Fig. 10. Experimental set up 
Particular attention is paid to center the load with respect to the saddle axis, in order to avoid undesired torque. The load is applied by means of a pneumatic actuator acting on the winglet with a corresponding load of $15 \mathrm{~kg}$. This force is monitored by a load cell sensor, as showed in Fig. 10. The operating pressure of compressed air conveyed in the pneumatic actuator is $P=3$ bar.

The frequency of the applied load is guaranteed by micro-switches and relays devices. The dynamic excitation main characteristics are summarized in Table 4.

Table 4.

Cycle load characteristics

\begin{tabular}{|c|c|c|}
\hline Frequency $[\mathrm{Hz}]$ & $N$ of cycles & Acquisition time $[\mathrm{h}]$ \\
\hline 1.6 & 20000 & 3.47 \\
\hline
\end{tabular}

A short running test of $100 \mathrm{~s}$ is provided in Fig. 11. The time evolution plot reporting all the sensors is provided to verify the matching phases and synchronization signals. As expected, the sensors outputs are all in phase and their strain amplitude are in agreement with the numerical simulation and sensitivity factor (Fig. 8).

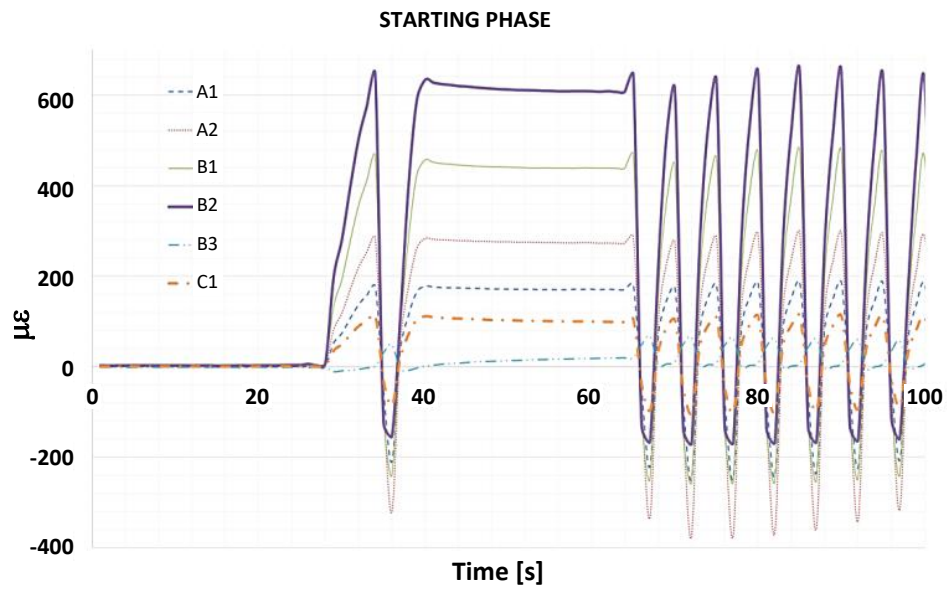

Fig. 11. Time evolution of strain sensors during the starting phase

The final test campaign started at 0 seconds and the acquisition has been logged for almost 3.4 hours. During the acquisition, an anomalous variation of the dynamic response occurred after about 1.5 hour, due to the skin-spar debonding. As example, the time evolution from sensor B3 is reported in Fig. 12.

During the acquisition, the time-varying spectrum of the FBGs is computed using a STFT to identify the moment of failure for long time measurements. A time-frequency analysis is particularly suited for diagnostics of transient signals such as impact-induced or flaws generation, due to its ability to isolate specific frequencies. Compared to other time-frequency analyses, STFT does not require 
B3

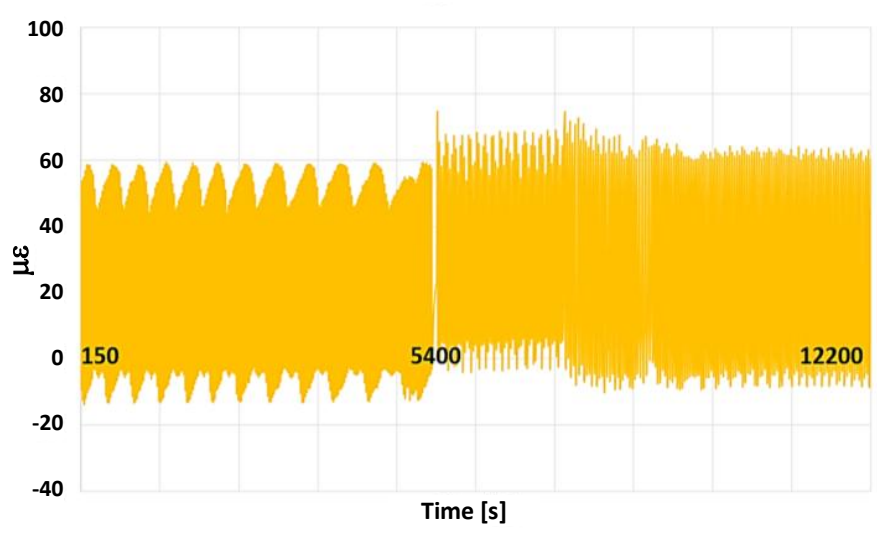

Fig. 12. B3 sensor full time acquisition

long computation time and therefore it may be applied in the real-time processing for failure detection at the expense of high-resolution analyses both in time and frequency simultaneously. Fig. 13 shows the strain wave signal due to the main spar debonding detected after about 1.5 hour from the beginning of the test campaign (in Fig. 13 time reference is indicated as $0 \mathrm{hrs}$ ). A change in the overall frequency content can be observed due to the detected failure resulting in more uniform distribution with lower amplitude frequency content along the range.

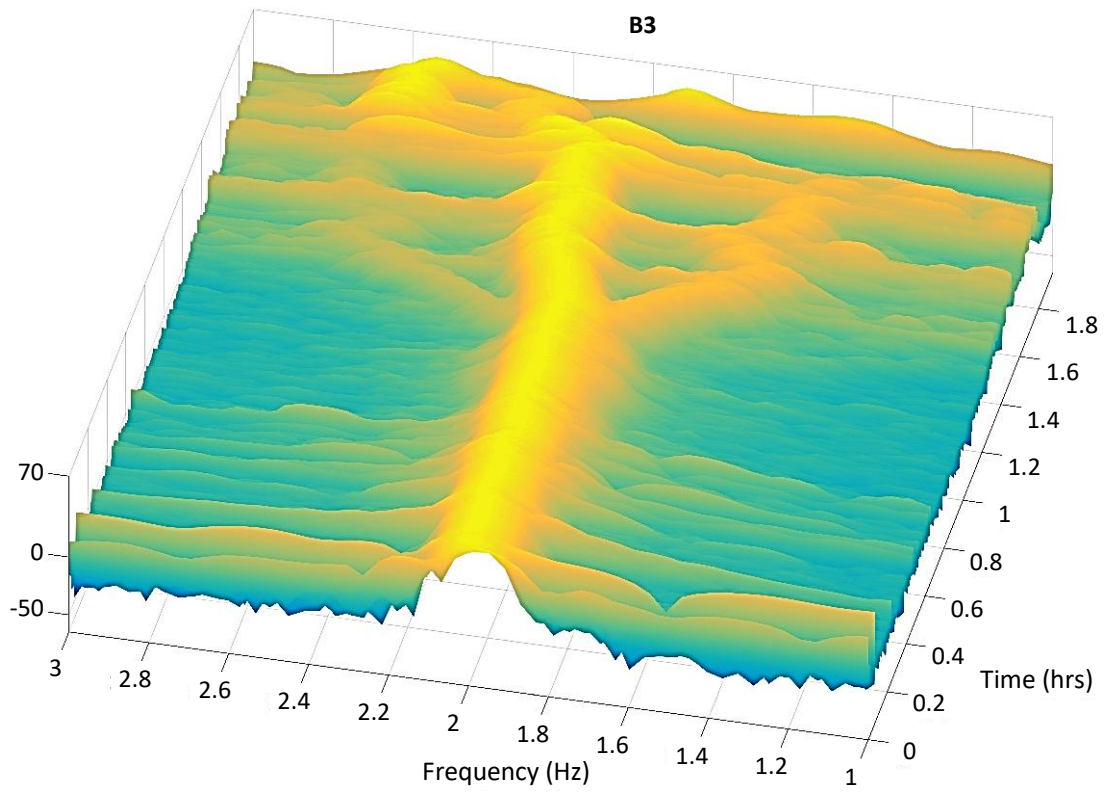

Fig. 13. Spectrogram of B3 signals showing the skin-spar debonding event 


\section{Conclusion}

The present work is focused on the implementation of a SHM methodology able to detect structural debonding during in-service operative life of a composite winglet. The Short Time Fast Fourier transform is applied to the real time acquisition of strain data set using FBG sensors network under cyclic load, for 3.4 hours. Structural dynamic response deviation from normal condition are detected, caused by the skin-spar bonding failure. The increment of the frequency content of sensors spectrogram is revealed by the analysis. In addition, lower amplitudes of additional sub-harmonics due to the damage are also observed. The high sensitivity of FBG sensors, and the low complexity integration procedure of the sensor network, made them a good choice for very high density monitoring issues and full scale applications.

Manuscript received by Editorial Board, December 15, 2016;

final version, June 09, 2017.

\section{References}

[1] K. Diamanti and C. Soutis. Structural health monitoring techniques for aircraft composite structures. Progress in Aerospace Sciences, 46(8):342-352, 2010. doi: 10.1016/j.paerosci.2010.05.001.

[2] C. Bockenheimer and H. Speckmann. Validation, verification and implementation of SHM at Airbus. In Proceedings of the 9th International Workshop on Structural Health Monitoring (IWSHM 2013), Stanford University, Stanford, CA, USA, pages 10-12, 2013.

[3] H. Speckmann and H. Roesner. Structual Health Monitoring: A contribution to the intelligent aircraft structure. In Proceedings of ECNDT 2006, 9th European Conference on NDT, Berlin, Germany, Sept. 2006.

[4] O. Shapira, S. Kedem, B. Glam, N.Y. Shemesh, A. Dvorjetski, N. Mashiach, J. Balter, R. Shklovsky, I. Sovran, N. Gorbatov, et al. Implementation of a fiber-optic sensing technology for global structural integrity monitoring of UAVs. In The 54th Israel Annual Conference on Aerospace Sciences, Tel-Aviv, Israel, 2014.

[5] R. De Oliveira, O. Frazão, J.L. Santos, and A.T. Marques. Optic fibre sensor for real-time damage detection in smart composite. Computers \& Structures, 82(17):1315-1321, 2004. doi: 10.1016/j.compstruc.2004.03.028.

[6] E. Di Lorenzo, G. Petrone, S. Manzato, B. Peeters, W. Desmet, and F. Marulo. Damage detection in wind turbine blades by using operational modal analysis. Structural Health Monitoring, 15(3):289-301, 2016. doi: 10.1177/1475921716642748.

[7] I. Dimino and A. Calabrò. Structural damage identification by vibration parametres and fibre optic sensors. Czech Aerospace, 2009(3):33-41, 2009.

[8] S. Bhalla and C.K. Soh. Structural health monitoring by piezo-impedance transducers. I: Modeling. Journal of Aerospace Engineering, 17(4):154-165, 2004. doi: 10.1061/(ASCE)08931321(2004)17:4(154).

[9] S. Bhalla and C.K. Soh. Electromechanical impedance modeling for adhesively bonded piezotransducers. Journal of Intelligent Material Systems and Structures, 15(12):955-972, 2004. doi: 10.1177/1045389X04046309. 
[10] A. De Fenza, A. Sorrentino, and P. Vitiello. Application of Artificial Neural Networks and Probability Ellipse methods for damage detection using Lamb waves. Composite Structures, 133:390-403, 2015. doi: 10.1016/j.compstruct.2015.07.089.

[11] R. Di Sante. Fibre optic sensors for structural health monitoring of aircraft composite structures: Recent advances and applications. Sensors, 15(8):18666-18713, 2015. doi: $10.3390 / \mathrm{s} 150818666$.

[12] H. Takeya, T. Ozaki, and N. Takeda. Structural health monitoring of advanced grid structure using multi-point FBG sensors. Proc. SPIE, 5762:204-211, 2005. doi: 10.1117/12.598759.

[13] H. Murayama, K. Kageyama, H. Naruse, A. Shimada, and K. Uzawa. Application of fiber-optic distributed sensors to health monitoring for full-scale composite structures. Journal of Intelligent Material Systems and Structures, 14(1):3-13, 2003. doi: 10.1177/1045389X03014001001.

[14] G. Fabbi, M. Ciminello, A. Mataloni, P. Perugini, A. Sorrentino, and A. Concilio. Filament wound solid rocket motor vessels strain measurement and potential Structural Health Monitoring through fiber optics. In The space Propulsion 201 Conference, Rome, Italy, 2-6 May 2016. Paper No. SP2016-3125185.

[15] M. Ciminello, I. Dimino, S. Ameduri, and A. Concilio. Fiber optic shape sensor for morphing wing trailing edge. In Proceedings of 26th International Conference on Adaptive Structures and Technologies (ICAST2015), pages 312-318, 14-16 Oct. 2015.

[16] J.R. Lee, C.Y. Ryu, B.Y. Koo, S.G. Kang, C.S. Hong, and C.G. Kim. In-flight health monitoring of a subscale wing using a fiber bragg grating sensor system. Smart Materials and Structures, 12(1):147, 2003. doi: 10.1088/0964-1726/12/1/317.

[17] A. De Fenza, G. Petrone, R. Pecora, and M. Barile. Post-impact damage detection on a winglet structure realized in composite material. Composite Structures, 169:129-137, 2017. doi: 10.1016/j.compstruct.2016.10.004.

[18] MD Nastran. Quick Reference Guide, 2011.

[19] K.O. Hill and G. Meltz. Fiber Bragg grating technology fundamentals and overview. Journal of Lightwave Technology, 15(8):1263-1276, 1997. doi: 10.1109/50.618320. 